\title{
DESIGNING PRODUCT METAPHOR TO PROMOTE SUSTAINABLE BEHAVIOUR: A PROPOSED METHOD
}

\author{
S. Huang ${ }^{1,2, \otimes}$, M. Carulli ${ }^{1}$, P. Hekkert ${ }^{2}$, R. N. J. Schifferstein ${ }^{2}$ and M. Bordegoni ${ }^{1}$ \\ ${ }^{1}$ Politecnico di Milano, Italy, ${ }^{2}$ Delft University of Technology, The Netherlands \\ $\bigotimes$ siyuan.huang@polimi.it
}

\section{Abstract}

Within the scope of Design for Sustainable Behaviour, the connection between behavioural change strategies and design idea generation has received limited attention. This paper highlights metaphorical thinking in product design to stimulate sustainable behaviour. In particular, the current study proposes a metaphor-based design method to guide designers on how to associate product features with behavioural and experiential cues through metaphors. We next report two design cases to evaluate this method. In the end, the shortcomings of current research and future developments are also discussed.

Keywords: design methodology, human behaviour, product design, sustainable design, ecodesign

\section{Introduction}

Human beings and societies are confronted with significant challenges related to sustainability issues. Over the past few decades, a broad concern on sustainable development or a sustainable society is raised by human activities and related environmental consequences (Robinson, 2007). A global agenda for reducing human ecological footprints and promoting sustainable behaviour is on the threshold of driving new possibilities for the future.

Design, as a powerful means for triggering positive behaviour change or mitigating the negative impact of problematic human behaviours, has been significantly addressed. In the early stage of sustainable design or design for sustainability, a majority of studies and practices were carried out in the sectors of mechanical manufacturing, industrial production and management (Bechtel and Jayaram, 1997; Foxon and Pearson, 2008). However, over the past decade, the disciplinary focus has gradually shifted to more psychological and social-oriented approaches. In particular, the design of products and services to prompt pro-environmental and pro-social behaviours (Boks et al., 2017). Furthermore, rather than the designed things, we should pay more attention to the relationship between humans and products (Verbeek, 2015). Thereby we can better understand the nature of design in shaping human impact on environmental and societal issues.

Within the scope of Design for Sustainable Behaviour (DfSB), the emphasis is on the mechanisms and design intervention strategies that can empower preferred behaviours or prevent undesired behaviours (Niedderer et al., 2017). However, limited attention has been given to the connection between behaviour change strategies with design idea generation (Coskun et al., 2015). The current paper presents a metaphor-based design method to guide designers on how to associate product features with behavioural 
and experiential cues through metaphors. Based on the method, we then report two design cases to investigate: (1) whether the use of metaphors in design can help designers generate ideas by explicitly organizing product expressions; (2) whether the users can grasp the metaphorical meanings (behavioural and experiential cues) and act in the desired way. In the end, we also discuss the shortcomings of current research and future developments by integrating user evaluation results and theoretical reflections.

\section{Related works}

This section starts with an introduction to Design for Sustainable Behaviour (DfSB). We then clarify the concepts and application values of metaphor in product design to promote sustainable behaviour.

\subsection{Design for sustainable behaviour}

Human activities do not happen in a vacuum. We are all exposed to a designed world where products and services in our surrounding environment affect the way we perceive, interpret, and act/behave. Thus, on the theme of human impact on the environment and sustainable development, an increasing emphasis has been placed on the mediating effect of products on human behaviours. In particular, the use phase of products, such as the way that people interact with the designed artefact. This narrative is consistent with the semiotic notion of "script", that is, the material structure of a design prescripts user behaviour in a specific direction (Jelsma, 2006). Moreover, it is similar to the concept of "perceived affordance" provided by visual cues of a product (Norman, 1999).

Next to the pragmatic meanings provided by the product, the other side of this coin should also be emphasised, that is, the experiential meanings offered by a product's expression. For example, a cup not only provides a visual form that affords pick-up-ability; the physical characteristics such as shape and texture will also affect people's experience while using it. If the cup is an exquisite souvenir, then it will also embed additional aesthetic and memorial meanings. Therefore, to stimulate the designer's creativity in designing products to promote sustainable behaviour, the focus of design should not be limited to product usability and functionality. It should also encompass the creation and delivery of multiple product experiences such as emotional, semantic, and aesthetical responses (Schifferstein and Hekkert, 2008), as well as social and cultural implications like ethical and moral concerns.

In the past decade, scholars have linked behavioural theories rooted in a diverse range of disciplines (e.g., social and behavioural sciences, environmental psychology) to the field of design. The intention of building up theoretical methods and frameworks is to help the implementation of design practices (Bhamra et al., 2011; Fogg, 2009; Michie et al., 2011). However, given various design strategies at hand, designers are still unclear about how to reach the behavioural design goal during the design process, particularly in the ideation stage. To embed metaphorical thinking in design is a promising direction that can guide designers through the course of design conceptualisation, especially when the behavioural design strategies function together. Meanwhile, in terms of employing metaphorical expressions in the designed artefacts, it also influences people's way of perceiving, experiencing and acting.

\subsection{The power of metaphor}

In a nutshell, a metaphor describes one thing in terms of another. The prevalent use of metaphor in communication can denote complex or abstract concepts in terms of concrete expressions. For instance, the saying of "I have butterflies/knots in my stomach." describes a sense of nervousness and excitement by making use of the figurative representations, such as living creatures or physical objects that can be seen in people's daily lives. Thus, this kind of metaphorical expression leads to a more comprehensive and vivid understanding of conceptual ideas such as feelings, emotions, and other experiences that are otherwise hard to grasp.

The core of establishing a metaphor is the source-target association, which means projecting the identified properties from a source domain to a target domain to create new meanings. However, the new meanings generated are not restricted to specific thoughts and ideas, but also open up new ways for experience and behaviour. In the aforementioned example, the source domain is a scene gathering a group of flying butterflies or a chain of twisted ropes. The target domain is the overall feeling aroused, through which people's cognitions, decision-makings and action tendencies can be 
influenced. In this case, the listener may wonder how to ease the speaker's burden by untying the rope or getting rid of the butterflies. Therefore, the use of metaphor goes far beyond figurative language because it stands for a significant part of human thinking, reasoning and acting (Lakoff, 1993).

Admittedly, the role of metaphor has been multi-disciplinarily explored due to its capacity to structure thoughts, transform experience, elicit emotions, and influence evaluations (Sopory and Dillard, 2002). In the field of design, the conceptual metaphor has long been credited for its various merits. On the one hand, it bridges designers' metaphorical thinking with analogical reasoning to create meaningful human-product interactions (Blackwell, 2006). On the other hand, it facilitates effective communication between designers and users (Saffer, 2005), which affects the delivery of product expressions, as well as the way people think and behave (Lakoff and Johnson, 2013).

In the early days of interaction design, conceptual metaphors played an instrumental role in user interface design (e.g., a recycle bin for file deletion and an envelope for the mailbox). Because it can initially ease the user's cognitive burden when using computing systems (Carroll and Thomas, 1982). Moreover, as researchers' interests shift from screen-based interactions to hybrid tactile/tangible interactions, metaphor in physical products has been increasingly addressed (Ishii and Ullmer, 1997).

\subsection{Metaphor in product design for promoting sustainable behaviour}

The use of metaphor in (physical) product design to simulate sustainable behaviour is not uncommon. "Blikvanger" (can-catcher in English), a net-capture shaped trash bin, was implemented along the Dutch highways to reduce littering on roads (Tromp et al., 2011). In this case, the designer intentionally linked the idea of capturing things with the target action of throwing items. By transferring the characteristics of the trapping net (source) to the trash bin (target), the metaphor in this product creates new meanings to the existing behaviour of waste disposal. In practice, it invites people to behave in an intuitive and desired way. On the experiential side, it motivates people to act in terms of taking a challenge for fun.

A product metaphor is defined by Hekkert and Cila (2015) as "any kind of product whose design intentionally references the physical properties of another entity for specific, expressive purposes". The last phrase, expressive purposes can be understood with the discussion on pragmatic and experiential intentions of designers in Section 2.1. On the one hand, the goal can be to provide operational cues or ways of interaction with the product. Similar to the concept of perceived affordance, Van Rompay and Ludden (2015) classified different types of embodiment in product experience. These explicitly refer to the perception and response to product action and movement. On the other hand, the purpose of using metaphor in product design is not limited to eliciting desired human behaviours but also aims for adding new meanings to product experiences. In particular, the new meanings are inspired and transferred by metaphorical projection onto the physical properties of the designed artefacts.

Many scholars have identified that metaphors in product design can vary from innate/embodied ones to cultural/learned ones, as well as creative/novel ones (Cila, 2013; Forceville and Urios-Aparisi, 2009; Hurtienne and Israel, 2007). When designers intentionally associate people's bodily or sensorimotor interactions in the physical environment with product design, they construct embodied product metaphors (Hurtienne and Blessing, 2007). Like the Blikvanger case, it utilises people's sensorimotor experience of capturing things with a net and invites the actions of targeting and throwing items into the net. Concerning the learned or cultural metaphors in products, they refer to design manifestations made by linking people's expertise and knowledge gained in the cultural and social environment with product design. For instance, a dartboard-shaped ashtray was designed and implemented in the campus area to tackle the problem of cigarette butts littering. By transferring the prominent characteristics (e.g., the dartboard has several segments, and the player should target at the centre with a small dart) in the source domain (darts) to the target domain (cigarette bin), this product effectively prompts the smokers' behaviour of aiming and throwing their cigarette butts at the centre ring (Huang et al., 2019). Thus, this work turns careless littering into an engaging game by applying learned metaphors in product design.

In summary, to convey the intended behavioural and experiential cues through product metaphors, the designer should outline the associated meanings and action possibilities that the users can perceive. In other words, designers should draw a meaningful connection between the users' prior experiences of familiar things/situations with the materiality of interactive artefacts (Jung et al., 2017). 


\section{Designing product metaphor to promote sustainable behaviour: a proposed method}

This section presents a metaphor-based design method that aims at facilitating the ideation process in DfSB. In particular, it shows how to associate product characteristics with behavioural and experiential cues through metaphors. Figure 1 illustrates a flowchart of the method that consists of the following stages:

1. Analysis of the target behaviour and context. The first stage in this method is to identify and examine the patterns of target behaviours and corresponding contextual factors to understand both the implicit and explicit behavioural mechanisms.

2. Design of the product metaphor. This stage consists of four steps.

a) Source selection. This step is about exploring and deciding a metaphorical source. For instance, the darts game is the selected source for the cigarette bin case mentioned earlier.

b) Source-target association. This step is the identification of the source characteristics that can be transferred to the design target. For example, features in the game of darts include different segments of the dartboard and the player should pay great attention while aiming at the centre.

c) Specification on the intended meaning. This step is to specify and determine the experiential and behavioural purposes that the design target should embed, which, in turn, can provide a concrete basis for the next step. In the case of the cigarette receptacle, the intended behavioural cue is to invite smokers to aim and throw cigarette butts towards the centre of the container. The intended experiential prompt is a gamified challenge.

d) Metaphorical mapping/projection. Based on the previous steps, the designer is expected to project the identified source characteristics to the product attributes (e.g., shape, colour, sound, movement, smell, and interaction) of the design target. For instance, the container part of the ashtray is shaped and coloured as a dartboard, which has three different layers. When a smoker hits the centre with a cigarette butt, a winning sound will be given to indicate success.

3. Development of the prototype. This stage involves the building of a virtual or physical prototype, even a mixed one. Depending on the required fidelity for assessing the priorly defined design concept, the designer is free to create a user experience prototype or working prototype.

4. User test and evaluation. To examine the understandability of the metaphorical meaning for the intended interaction, the designer needs to conduct preliminary user test with the developed prototype. This procedure helps designers to understand whether the implementation of product metaphors demonstrates pragmatic and experiential intentions.

Besides, as indicated by the arrow in the left side of Figure 1, an iterative process allows the designer to modify his/her design works based on user feedback.

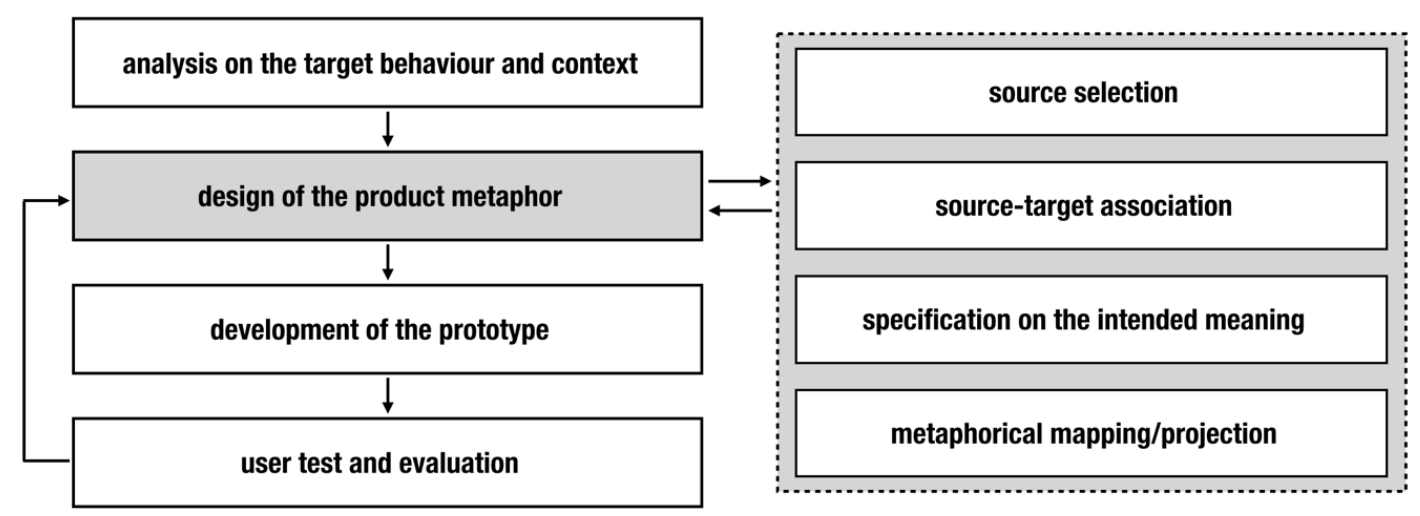

Figure 1. A graphical representation of the proposed method 


\section{Case studies}

This section presents two design cases as applications of the proposed method. In particular, two objectives were: (1) whether the proposed method can lead the designer's way of ideation, especially on structuring the meanings in human-product interaction; (2) whether it can give rise to novel and meaningful products or prototypes that can be understood by the target users.

Among many critical challenges identified in the field of DfSB (e.g., energy consumption reduction, water conservation, transportation and mobility issues), in this work, we focus on the theme of food consumption. Food waste alone stands for a significant proportion of individual carbon footprint (Popp et al., 2010) and also presents linkages to other major sectors (Munksgaard et al., 2000). Specifically, the first case pays attention to reducing excessive fruit waste in a household context. The latter case focuses on sustainable eating behaviour among young children.

\subsection{BANYAN BOWL: an interactive fruit bowl against food waste}

\subsubsection{Design of the product metaphor}

Through a preliminary analysis on fruit waste in households, we found out many people easily forget to consume fruits in time because it is both hard to keep notice of the fruit where they are placed after purchasing and to maintain track of the fruit condition. Also, some fruits are hidden beneath eyesight due to the depth of a conventional fruit bowl. Therefore, we determined that the design target should be a container that can not only preserve fruits but also remind/invite people to eat fruits at the right time.

After a series of explorations, the Banyan Bowl adopts the concept of a tree, which metaphorically stands for ecology and life. The green colour is firmly associated with the idea of nature, which can emphasise a thoughtful and eco-friendly lifestyle. Upon the selection of the primary source domain, we further specified other metaphorical components (see Table 1).

Table 1. An overview of product metaphors in the BANYAN BOWL case

\begin{tabular}{|c|c|c|c|c|c|}
\hline Source & Meaning & Property & Target & $\begin{array}{l}\text { Intended } \\
\text { meaning }\end{array}$ & $\begin{array}{c}\text { Abstraction } \\
\text { level }\end{array}$ \\
\hline Tree & $\begin{array}{l}\text { Nature, life and } \\
\text { healthiness }\end{array}$ & Shape & $\begin{array}{l}\text { Structure of fruit } \\
\text { bowl }\end{array}$ & $\begin{array}{l}\text { A growing environment of } \\
\text { fruits }\end{array}$ & Medium \\
\hline $\begin{array}{l}\text { The } \\
\text { trunk } \\
\text { and } \\
\text { roots }\end{array}$ & $\begin{array}{l}\text { Stability and } \\
\text { support }\end{array}$ & Shape & $\begin{array}{l}\text { The pedestal of } \\
\text { fruit bowl }\end{array}$ & $\begin{array}{l}\text { Robustness for holding } \\
\text { items }\end{array}$ & Low \\
\hline Leaf & Vitality & Shape and colour & Fruit tray & A placement area of fruits & Low \\
\hline $\begin{array}{l}\text { Fallen } \\
\text { leaves }\end{array}$ & $\begin{array}{l}\text { Sickness and } \\
\text { malnutrition }\end{array}$ & Spatial Movement & Branch & $\begin{array}{l}\text { Create awareness of the } \\
\text { fruit condition }\end{array}$ & High \\
\hline $\begin{array}{l}\text { Fallen } \\
\text { fruits }\end{array}$ & $\begin{array}{l}\text { Maturity and } \\
\text { ripeness }\end{array}$ & Interaction & Fruit & $\begin{array}{l}\text { An invitation of picking up } \\
\text { the fruits }\end{array}$ & High \\
\hline Metre & $\begin{array}{l}\text { Measurement and } \\
\text { calculation }\end{array}$ & Interaction & Control panel & $\begin{array}{l}\text { An invitation of rotating for } \\
\text { setting up }\end{array}$ & Medium \\
\hline $\begin{array}{l}\text { Banyan } \\
\text { tree }\end{array}$ & $\begin{array}{l}\text { Meanings related } \\
\text { to this species }\end{array}$ & Name & Product name & $\begin{array}{l}\text { A linkage of multiple } \\
\text { meanings }\end{array}$ & High \\
\hline
\end{tabular}

Among all the metaphorical connections made between the source and the design target, the main feature we projected is the spatial schema of tree leaves. Lakoff and Johnson (1980) explain that abstract concepts contain sensorimotor representations of relevant bodily states. In particular, an orientation metaphor like the downward movement of the branch can refer to sickness, bad condition and the end of life. Through this metaphorical mapping, users can easily compare the freshness of different fruits and decide which one to eat first based on the relative height of the fruit tray. Specifically, the lower height the fruits are placed, the more mature or staler they are. Thereby it can stimulate users to consume the fruits in time and to avoid possible wastes. 


\subsubsection{User test}

Based on the concept, a 3D model was created using Autodesk Fusion 360 and Autodesk Inventor. Then, a virtual reality scenario was further developed by using the Unity3D game engine (www.unity3d.com). In total, four subjects voluntarily participated in the evaluation session that consists of three parts.

In the first part, participants were asked about their ideas towards a group of 3D model rendering images (a front view is shown on the left side of Figure 2). Questions were concentrated on the identification of the metaphorical source and associated meanings with its properties. Most of the participants identified the primary metaphor as a tree, together with other detailed features, and only one subject was more prone to see it as a flower because of the dimensions of the components.

In the second part, all participants were presented with a scenario of them arriving at home with purchased fruits to store. To be specific, the users were invited to navigate in a kitchen scenario (in the first-person view) and to interact with the virtual prototype. The interaction session consists of several steps: placing fruits on the leaf-trays; selecting the branch and fruit category by interacting with the user interface; setting the expected time of consumption according to the suggested life span. Upon the placement of the set-up, the fruit starts moving down along the tree trunk. Finally, an empty tray will return to its top position (The interaction flow of the prototype is shown on the right side of Figure 2).

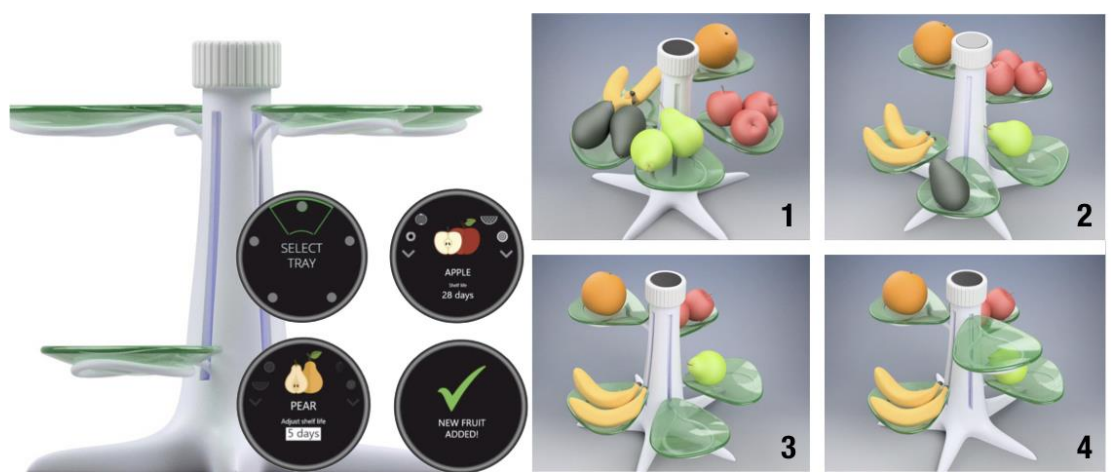

Figure 2. Left side: Prototype outline and the user interface; Right side: Interaction flow

In the second part of the user test, subjects were kindly inquired about their perceptions of this up-down scheme movement. Among all the feedbacks, an impressive one from a male participant suggested that a bottom-up scheme would lead to a feeling of easy access to the fruits, particularly from a horizontal view. Moreover, the metaphor in this interpretation can be seen as a servant holding up a dish in a buffet scenario. This unexpected interpretation is opposite to the intended meanings in the up-down motion, and we assume it may result from the primarily recalled experience of the user when interacting with the prototype.

Finally, participants' willingness to use this product in real life and suggestions for improvement were also collected. Participants unanimously declared they saw a high potential of this product concept in the market, and they thought it could help the household in reducing fruit waste. Moreover, participants also discussed the moving speed of the branch and the level of intelligence of this product. Concerning the last point, further explorations on how to detect and provide more accurate shelf life suggestions could be done in the future with humidity detectors, thermometers and UV readings.

\subsection{FUN\&GO: an interactive food container to promote sustainable and healthy eating in early childhood education}

\subsubsection{Design of the product metaphor}

The purpose of developing FUN\&GO is to guide young children to adopt healthy and sustainable eating behaviour in a playful way. Therefore, we designed an interactive container that can store food (e.g., fruits, nuts, and bread) at room temperature. Because the target audience is young kids, we identified two main characteristics related to children's tendency to try new things and acquire new knowledge: one is the nature of imitation and play, and the other is the arousal of curiosity and attention.

After several explorations, a typical kind of mushroom was picked as the primary metaphorical source (illustrated in Table 2). This prototype was created to inform children how long food can last through a metaphorical projection 
of mushroom's decomposition features. In fact, fungi decompose in nature due to environmental humidity and the growth of mildew and insects. Accordingly, we designed a mushroom-shaped food container, with gradually appearing insects over time. This colourful visual expression is intended to trigger kids' curiosity to play with the box. In particular, when children push to open the container, they can intuitively understand how fresh the food is by observing the number of insects on the lid.

Table 2. An overview of product metaphors in the FUN\&GO case

\begin{tabular}{|l|l|l|l|l|l|}
\hline \multicolumn{1}{|c|}{ Source } & \multicolumn{1}{|c|}{ Meaning } & \multicolumn{1}{|c|}{ Property } & \multicolumn{1}{c|}{ Target } & \multicolumn{1}{c|}{$\begin{array}{c}\text { Intended } \\
\text { meaning }\end{array}$} & $\begin{array}{l}\text { Abstraction } \\
\text { level }\end{array}$ \\
\hline Mushroom & $\begin{array}{l}\text { Nature (wood and forest) } \\
\text { and organism }\end{array}$ & $\begin{array}{l}\text { Form, colour } \\
\text { and graphics }\end{array}$ & Food container & Intimacy towards nature & Low \\
\hline $\begin{array}{l}\text { Mushroom } \\
\text { cap }\end{array}$ & Vitality and cuteness & $\begin{array}{l}\text { Form, colour } \\
\text { and graphics }\end{array}$ & $\begin{array}{l}\text { The lid of the } \\
\text { container }\end{array}$ & $\begin{array}{l}\text { Arouse curiosity for } \\
\text { checking }\end{array}$ & Medium \\
\hline Insect & $\begin{array}{l}\text { Decomposition and } \\
\text { change of freshness }\end{array}$ & $\begin{array}{l}\text { Colour and } \\
\text { graphics }\end{array}$ & $\begin{array}{l}\text { The lid of the } \\
\text { container }\end{array}$ & $\begin{array}{l}\text { Embed a sense of } \\
\text { avoidance }\end{array}$ & High \\
\hline $\begin{array}{l}\text { Sound } \\
\text { effect }\end{array}$ & A result indicator & Sound & Audio Feedback & $\begin{array}{l}\text { Indicating the food is } \\
\text { edible or not }\end{array}$ & Medium \\
\hline "Fun\&go" & $\begin{array}{l}\text { "Fungo" means } \\
\text { mushroom in Italian }\end{array}$ & Name & Product name & $\begin{array}{l}\text { A linkage of multiple } \\
\text { meanings }\end{array}$ & High \\
\hline
\end{tabular}

Moreover, we also added two kinds of audio feedback to indicate whether the food inside is edible. For security reasons, the physical product can also connect to a digital application managed by parents. As a result, young children can learn how to prevent food waste in a joyful way, and parents can monitor through the digital app when their kids are eating.

\subsubsection{User test}

A working prototype was developed by using the Arduino Uno board (www.arduino.cc) in connection with an application developed by using the Unity3D game engine (www.unity3d.com). The connection is realised via a Bluetooth HC-06 module, which allows direct control from the application to the container. The developed board can convert the received values as inputs to the timer. After the user presses the lid, a button will be initiated to start the timer, which in turn, will release the light from zero to four LEDs. Projections of animated shadows of four different kinds of animals will then be displayed accordingly on the lid (as shown in the left side of Figure 3). At the same time, audio feedback as a safety reminder is transmitted and delivered through a piezo speaker.

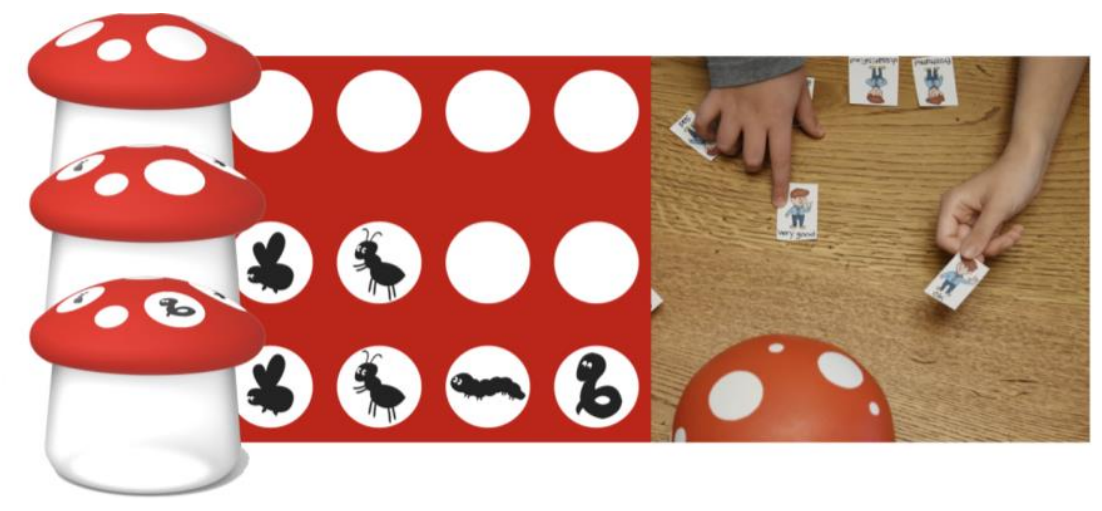

Figure 3. Left side: Design of the metaphorical feedbacks; Right side: User test

To verify the metaphorical information is understandable to young kids, semi-structured interviews were conducted. A total of five children, mean age 8.6, and their parents participated in the user test. As shown on the right side of Figure 3, we adopted the Picture Cards Method (Barendregt et al., 2008) to enable children to express themselves more accurately during the testing session. Specifically, the kids were provided with a box of picture cards that symbolise different types of appraisals (e.g., frustrated, dissatisfied, afraid, ok, good, and very good). After a brief introduction, the kids were invited to a free trial of the physical prototype. Meanwhile, the parents were presented with the mobile application. 
According to the programmed settings, the children received a different type of feedback each time they pressed the lid. After completing the operation, four main questions were asked: (1) clarity of using the prototype; (2) comprehensibility of the metaphorical information; (3) whether this type of interaction triggered them to consume the food in time and (4) suggestions for further modification.

As a result, the children's feedback confirmed the intended interaction. They found the container has a visual reference to mushrooms that was adorably shaped, which, in turn, triggered their motivation to use it. Besides, it was easy for the kids to associate the product metaphor with the food condition. However, one child suggested resizing the product since the current size exceeded the capacity of his backpack. Also, parents were satisfied with the application, especially the security alert feature. Therefore, this meal box promotes safe and sustainable food consumption among young children, especially when they are in the habituation phase. Through this playful learning approach, kids can be expected to gain practical knowledge of healthy and sustainable eating in their daily routine.

\section{Conclusion}

This paper highlights metaphorical thinking in design to promote sustainable behaviour by locating a gap between theory and practice in the field of DfSB. We propose a metaphor-based design method aimed at facilitating the design process. Besides, in the context of reducing individual ecological footprint through product use, two design cases are implemented to tackle the unsustainable behaviour of food waste. The results show a promising future for using the design method to broaden design perspectives, especially in structuring products' interactive features. At the same time, the designed prototypes also indicate that the users can understand the embedded meanings in product metaphors, in particular, the behavioural and experiential cues. Whereas the product metaphor can also achieve the goal of eliciting intended sustainable behaviours in real-world settings deserves further examination.

\section{Discussion and future work}

The current study has limitations that need to be addressed together with possible modifications for future development. For the case of the BANYAN BOWL, a broader scope of evaluation and validation on refined product metaphors is worth investigating. For instance, a comparison between the up-down and the bottom-up schema of the fruit tray movement will be a promising direction for future research. Specifically, the primary purpose of using metaphorical expressions in interactive artefacts is to relive the cognitive burden and lead to intuitive and meaningful user behaviour. However, in the BANYAN BOWL case, some people may tend to pick up the fruit while it is more approaching to the body, and others may consider the fruits kept in low position means they are ripe and ready to be eaten.

Concerning the case of the FUN\&GO, it would be more feasible to reframe the target user group to pre-schoolers. Because young children aged above six nowadays are exceedingly exposed to electronic technologies, as a so-called digital childhood (Vandewater et al., 2007), they will be less motivated to adjust themselves to such metaphorical interaction. Moreover, another inspection will concern whether there is a negative affection elicited by the metaphorical feedbacks of the mushroom. The current shape and colour of the container is confusing and could be perceived as Amanita muscaria. It is a typical fungus that classified as poisonous to eat and may lead to hallucination. So, in the next prototype, we should modify the design to avoid misunderstandings. Also, kids may find the metaphorical insects on the lid are hilarious to play with rather than taking them as serious indicators. As we discussed earlier in this paper, metaphor owns many advantages in design. It can help designers envision meaningful human-product interactions in the design ideation stage, and it can facilitate the communication between designers and users by structuring product expressions. However, metaphors in design should be "handled with care" (Hekkert and Cila, 2015). For example, the visual metaphor adopted in the FUN\&GO case could be counterintuitive to knowledgeable audiences, which will also cause unexpected operation and use. Therefore, it is vital to highlight the iterative process in this method, which require designers to modify their design concepts/prototypes through user testing and evaluation.

Critical to the purpose of promoting sustainability through product design, the environmental impact caused by the production and distribution of these products may also demand plastic materials and 
other resources. Moreover, it is questionable to compensate for the reduced food waste by the use of electricity for powering these products. However, the focus of the proposed method is to see if using metaphor in product design can help designers to explore and expand design possibilities, rather than assisting them to identify and determine the final design outcome in a systematic way.

In both cases, our method aroused the designer's creativity and metaphorical thinking in designing for sustainable behaviour through metaphors. However, we need to keep a note that individuals see and interpret things differently. Thus, it is essential to understand the ambiguity and uncertainty in people's perception and comprehension towards conceptual metaphor. On selecting the primary source for the meaning association, the designer should be prone to human universals or principles. Because they fundamentally recall people's innate and sensorimotor experience in familiar scenarios or activities that can help to realise the purpose of this method.

More importantly, sub-questions like:

- how can the designer balance the abstraction level and the depth of metaphorical mappings on product properties for intended interaction? In other words, what aspect and what degree of representation of the source meaning can deliver effective communication for behaviour change?

- how should one match pragmatic and experiential meanings on product metaphor, particularly the embodied ones with the users' behavioural habits or preferences to achieve intuitive interactions that require less cognitive load?

- how can we employ maximum effect for minimum means (Da Silva et al., 2016) to attain simplicity, efficiency, and authenticity in product expressions?

are thought-provoking and meaningful directions for further exploration and development.

Last but not least, it is worth executing a diverse range of case studies regarding different technological approaches (e.g., mobile application, augmented reality, and mixed reality), which, in turn, will bring new thoughts and ideas into the current design method. Practical design guidelines can also be developed for the main stages of the proposed method (e.g., criteria for source selection and principles for metaphorical mapping/projection) to further facilitate the design ideation process.

\section{References}

Barendregt, W., Bekker, M.M. and Baauw, E. (2008), "Development and evaluation of the problem identification picture cards method", Cognition, Technology and Work, Vol. 10 No. 2, pp. 95-105. https://doi.org/10.1007/s10111-007-0066-z

Bechtel, C. and Jayaram, J. (1997), "Supply Chain Management: A Strategic Perspective”, The international Journal of Logistics Management, Vol. 8 No. 1, pp. 15-34. https://doi.org/10.1108/09574099710805565

Bhamra, T., Lilley, D. and Tang, T. (2011), "Design for Sustainable Behaviour: Using products to change consumer behaviour", The Design Journal, Vol. 14 No. 4, pp. 427-445. https://doi.org/10.2752/ $175630611 X 13091688930453$

Blackwell, A.F. (2006), "The reification of metaphor as a design tool", ACM Transactions on Computer-Human Interaction, Vol. 13 No. 4, pp. 490-530. https://doi.org/10.1145/1188816.1188820

Boks, C., Lilley, D. and Pettersen, I.N. (2017), "The future of design for sustainable behaviour revisited", In: Matsumoto M., Masui K., Fukushige S., Kondoh S. (Ed.), Sustainability Through Innovation in Product Life Cycle Design. EcoProduction (Environmental Issues in Logistics and Manufacturing). Springer, Singapore, pp. 675-689. https://doi.org/10.1007/978-981-10-0471-1_46

Carroll, J.M. and Thomas, J.C. (1982), "Metaphor and the cognitive representation of computing systems", IEEE Transactions on Systems, Man and Cybernetics, Vol. 12 No. 2, pp. 107-116. https://doi.org/10.11 09/TSMC.1982.4308795

Cila, N. (2013), Metaphor we design by: The use of metaphor in product design, [PhD Thesis], Delft University of Technology. https://doi.org/10.4233/uuid:b7484b0f-9596-4856-ae9d-97c696f9de79

Coskun, A., Zimmerman, J. and Erbug, C. (2015), "Promoting sustainability through behavior change: A review”, Design Studies, Elsevier, Vol. 41, pp. 183-204. https://doi.org/10.1016/j.destud.2015.08.008

Fogg, B.J. (2009), “A behavior model for persuasive design”, Proceedings of the 4th International Conference on Persuasive Technology, California, Claremont, USA, April 26-29, 2009, Association for Computing Machinery, New York, pp. 1-7. https://doi.org/10.1145/1541948.1541999

Forceville, C. and Urios-Aparisi, E. (2009), Multimodal Metaphor, Walter de Gruyter. Berlin. https://doi.org/ 10.1515/9783110215366.1.19 
Foxon, T. and Pearson, P. (2008), "Overcoming barriers to innovation and diffusion of cleaner technologies: some features of a sustainable innovation policy regime", Journal of Cleaner Production, Vol. 16 No. 1, pp. 148-161. https://doi.org/10.1016/j.jclepro.2007.10.011

Hekkert, P. and Cila, N. (2015), "Handle with care! Why and how designers make use of product metaphors", Design Studies, Vol. 40, pp. 196-217. https://doi.org/10.1016/j.destud.2015.06.007

Huang, S. et al. (2019), "AIM: An interactive ashtray to support behavior change through Gamification", Proceedings of the Design Society: International Conference on Engineering Design, Delft, the Netherlands, August 5-8, 2019, Cambridge University Press, pp. 3811-3820. https://doi.org/10.1017/dsi. 2019.388

Hurtienne, J. and Blessing, L. (2007), "Metaphors as tools for intuitive interaction with technology", Metaphorik.De, Vol. 12 No. 2, pp. 21-52.

Hurtienne, J. and Israel, J.H. (2007), "Image schemas and their metaphorical extensions: Intuitive patterns for tangible interaction", TEI'07: Proceedings of the 1st International Conference on Tangible and Embedded Interaction, pp. 127-134. https://doi.org/10.1145/1226969.1226996

Ishii, H. and Ullmer, B. (1997), "Tangible bits: Towards seamless interfaces between people, bits and atoms", Proceedings of the ACM SIGCHI Conference on Human Factors in Computing Systems, pp. 234-241.

Jelsma, J. (2006), "Designing 'moralized' products", In: Verbeek PP., Slob A. (Ed.), User Behavior and Technology Development: Shaping Sustainable Relations Between Consumers and Technology Development. Springer, Dordrecht, pp. 221-231. https://doi.org/10.1007/978-1-4020-5196-8_22

Jung, H. et al. (2017), "Metaphors, materialities, and affordances: Hybrid morphologies in the design of interactive artifacts", Design Studies, Vol. 53, pp. 24-46. https://doi.org/10.1016/j.destud.2017.06.004

Lakoff, G. (1993), "The contemporary theory of metaphor", In: A. Ortony (Ed.), Metaphor and Thought. Cambridge University Press, Cambridge, pp. 202-250.

Lakoff, G. and Johnson, M. (1980), "Conceptual metaphor in everyday language”, The Journal of Philosophy, Vol. 77 No. 8, pp. 453-486. https://doi.org/10.2307/2025464

Lakoff, G. and Johnson, M. (2013), Metaphor We Live By, University of Chicago Press, Chicago. https://doi.org/10.7208/chicago/9780226470993.001.0001

Michie, S., van Stralen, M.M. and West, R. (2011), "The behaviour change wheel: A new method for characterising and designing behaviour change interventions", Implementation Science, Vol. 6 No. 1, https://doi.org/10.1186/1748-5908-6-42

Munksgaard, J., Pedersen, K.A. and Wien, M. (2000), "Impact of household consumption on $\mathrm{CO}_{2}$ emissions", Energy Economics, Vol. 22 No. 4, pp. 423-440. https://doi.org/10.1016/S0140-9883(99)00033-X

Niedderer, K., Clune, S. and Ludden, G. (2017), Design for Behaviour Change: Theories and Practices of Designing for Change, Routledge, London. https://doi.org/10.4324/9781315576602

Norman, D.A. (1999), "Affordance, conventions, and design", Interactions, Vol. 6 No. 3, pp. 38-43. https://doi.org/10.1145/301153.301168

Popp, A., Lotze-Campen, H. and Bodirsky, B. (2010), "Food consumption, diet shifts and associated non-CO greenhouse gases from agricultural production”, Global Environmental Change, Vol. 20 No. 3, pp. 451-462. https://doi.org/10.1016/j.gloenvcha.2010.02.001

Robinson, J.B. (2007), Life in 2030: Exploring a Sustainable Future for Canada, UBC Press, Vancouver. https://doi.org/10.5860/choice.34-5396

Van Rompay, T.J.L. and Ludden, G.D.S. (2015), "Types of embodiment in design: The embodied foundations of meaning and affect in product design”, International Journal of Design, Vol. 9 No. 1, pp. 1-11

Saffer, D. (2005), The Role of Metaphor in Interaction Design, [Master Thesis], Carnegie Mellon University.

Schifferstein, H.N.J. and Hekkert, P. (2008), Product Experience, Elsevier. https://doi.org/10.1016/B978-0-08045089-6.X5001-1

Da Silva, O., Crilly, N. and Hekkert, P. (2016), "Maximum effect for minimum means: The aesthetics of efficiency”, Design Issues, Vol. 32 No. 1, pp. 41-51. https://doi.org/10.1162/DESI_a_00363

Sopory, P. and Dillard, J.P. (2002), "The persuasive effects of metaphor: A meta-analysis", Human Communication Research, Vol. 28 No. 3, pp. 382-419. https://doi.org/10.1093/hcr/28.3.382

Tromp, N., Hekkert, P. and Verbeek, P.P. (2011), "Design for socially responsible behavior: A classification of influence based on intended user experience", Design Issues, Vol. 27 No. 3, pp. 3-19. https://doi.org/10.1162/DESI_a_00087

Vandewater, E.A. et al. (2007), "Digital childhood: electronic media and technology use among infants, toddlers, and preschoolers", Pediatrics, Vol. 119 No. 5, pp. e1006-e1015. https://doi.org/10.1542/peds.2006-1804

Verbeek, P.P. (2015), "Cover story: Beyond interaction: A short introduction to mediation theory", Interactions, Vol. 22 No. 3, pp. 26-31. https://doi.org/10.1145/2751314 